\title{
Note
}

\section{Adsorptive Removal of Nitrate from Water Using Modified Activated Carbon Fibers}

\author{
Motoi MACHIDA ${ }^{1,2^{*}}$ and Yoshimasa $\mathrm{AMAMO}^{1,2}$ \\ ${ }^{1}$ Safety and Health Organization, Chiba University, 1-33 Yayoi-cho, Inage-ku, Chiba 263-8522, Japan \\ ${ }^{2}$ Graduate School of Engineering, Chiba University, 1-33 Yayoi-cho, Inage-ku, Chiba 263-8522, Japan
}

(Manuscript received April 2, 2018; accepted May 2, 2018)

\begin{abstract}
Activated carbon fiber (ACF) from cellulose based ACF (KF1500) was modified to give anion ion exchange functionality using three sequential modification methods; acetonitrile thermal chemical vapor deposition (CVD) at $800^{\circ} \mathrm{C}$, heat treatment at $950^{\circ} \mathrm{C}$ and then steam activation at $800^{\circ} \mathrm{C}$ for the purpose of maximizing ion exchange capacity of nitrate $\left(\mathrm{NO}_{3}{ }^{-}\right)$. The maximum adsorption amount of $0.71 \mathrm{mmol} / \mathrm{g}$ was achieved, which was 1.9 times larger than non-modified original KF1500 $(0.38 \mathrm{mmol} / \mathrm{g})$ but a half the amount of ion exchange resin of HP555 $(1.4 \mathrm{mmol} / \mathrm{g})$, under the same experimental conditions.
\end{abstract}

Keywords: Ion exchange, Activated carbon fiber, Adsorption of nitrate, Nitrogen doping, Acetonitrile thermal CVD

\section{Introduction}

Globally widespread contamination problems in air, land and water have already been attracted attention in this half a century. However, the situations are still going worse in developing countries, although strict environmental regulations have been introduced in developed countries. In this study, development of carbonaceous adsorbents is carried out to efficiently remove ionic pollutants from water in order to contribute to the conservation of water environment. Adsorptive removal of ionic pollutants is generally progressed via ion-exchange mechanism. For cation exchange resins, $\mathrm{Na}^{+}$ is released to aqueous phase when cationic heavy metal ions such as $\mathrm{Pb}^{2+}, \mathrm{Cd}^{2+}$ and $\mathrm{Cs}^{+}$adsorb to the resins, while $\mathrm{Cl}^{-}$is discharged into water in case of the adsorption of anionic contaminants like $\mathrm{NO}_{3}^{-}, \quad \mathrm{F}^{-}$and $\mathrm{H}_{2} \mathrm{PO}_{4}^{-}$. In general, carbonaceous adsorbents, typically activated carbon (AC) and activated carbon fiber (ACF), have been employed to uptake non-ionic organic pollutants using the hydrophobic interaction between the organic contaminants and graphene surfaces of AC and $\mathrm{ACF}{ }^{1)}$. In contrast, for the removal of ionic pollutants, hydrophilic surface is required whether they are cationic or anionic contaminants. Ceramic adsorbents such as zeolites and shells are good for both cationic and anionic pollutants, because there are electron rich and deficient sites simultaneously on the ceramic surfaces. As for ion exchange resins, carboxy and sulfonic functions are operative for cation adsorption, while quaternary nitrogen (N-Q) contributes to anion adsorption. Although the ceramic and resin adsorbents are widely used for both laboratory and commercial scales, acidic and basic conditions are not preferable for ceramics and heat treatment should be avoided for ion exchange resins. As mentioned above, carbonaceous materials, ceramics and ion exchange resins have advantages and disadvantages each other.

In this study, we have tried to develop new ACFs to capture ionic pollutants on the graphene surface of them by various modifications of carbon surfaces, because carbonaceous materials are tolerant of acid/base solution and heating stress. Suitable surface of ACs and ACFs for attracting cationic contaminants could have been successfully prepared by the oxidation of carbon surfaces using several oxidants like concentrated $\mathrm{HNO}_{3} / \mathrm{H}_{2} \mathrm{SO}_{4}$ system ${ }^{2)}$ and aqueous solution of $\left(\mathrm{NH}_{4}\right)_{2} \mathrm{~S}_{2} \mathrm{O}_{8}{ }^{3)}$. For the present, we are trying to modify the

\footnotetext{
* Corresponding author

E-mail: machida@faculty.chiba-u.jp
} 
carbon surfaces suitable for removing anionic pollutants. Graphene surfaces themselves are good for the adsorption of anionic pollutants only in the acidic region, because a slightly negatively charged graphene sheet originated from $\pi$-electrons of condensed benzene rings can accommodate protons forming a positively charged carbon surface ${ }^{4}$. But the electron density on the graphene sheets is easily lowered by acidic oxygen functional groups remained on the peripherals of the graphite structures, thereby removing oxygen from graphene sheets by reduction is a good option to increase the adsorption amounts of anionic contaminants ${ }^{5)}$. However, the surface charges of graphene sheets are also altered by solution $\mathrm{pH}$. Introduction of specific nitrogen functionalities is another option to enhance the adsorption amount of anions. The quaternary nitrogen (N-Q) at peripheral and/or inside the graphene structures always positively charged, hence the attractive force toward anionic contaminants is working independent of solution $\mathrm{pH}^{6}$ ). Aliphatic amines of $\mathrm{p} K_{\mathrm{a}}$ values more than 9-10 are protonated ($\mathrm{NH}_{3}{ }^{+}$) in the range from acidic to $\mathrm{pH} 9-10^{7)}$ becoming suitable sites for anionic contaminants as well. Both quaternary nitrogen (N-Q) and aliphatic amine on the adsorbents have been proven to be effective for the adsorption of anions ${ }^{8)}$.

In the present study, surface reduction of activated carbon fibers (ACFs) and nitrogen doping on the graphite structure of $\mathrm{ACFs}$ were examined; surface reduction was carried out to maximize the $\pi$-electron density of graphene sheets and nitrogen doping was conducted in order to increase the quaternary nitrogen $(\mathrm{N}-\mathrm{Q})$ in the graphite structure. The evaluation of the prepared carbonaceous adsorbents was performed by the adsorptive removal of nitrate $\left(\mathrm{NO}_{3}{ }^{-}\right)$from aqueous solution.

\section{Experimental}

Activated carbon fiber (ACF) KF1500 LDA, hereafter denoted as KF, used in the study is purchased from Toyobo Co., Ltd., Japan. KF is produced from cellulosic fiber in an industrial scale. $\mathrm{KF}$ was dried in an oven at $110^{\circ} \mathrm{C}$ for $30 \mathrm{~min}$ before use, weighed (0.7-0.9 g) and placed in 30 ф quartz tube and heated up to desired temperature between 800 and $950^{\circ} \mathrm{C}$ with a horizontal cylindrical furnace to modify the graphene surface of KF. All heat treatments of KF were conducted under helium flow at $50 \mathrm{~mL} / \mathrm{min}$. Based on our preliminary study of preparation of more than 200 different modified samples (not shown here), three methods and their combinations were employed for the heat-treated modification; thermal chemical vapor deposition (CVD) by $20 \mathrm{~mL}$ charge of acetonitrile at $800^{\circ} \mathrm{C}$ for doping nitrogen onto KF surface (8AN20) ${ }^{9}$ ), steam activation by $30 \mathrm{~mL}$ water charge at $800^{\circ} \mathrm{C}$ for developing pore structure of $\mathrm{KF}(8 \mathrm{ST} 30)$, and just heating at $950^{\circ} \mathrm{C}$, holding time of $30 \mathrm{~min}$, for converting a part of doped nitrogen to quaternary nitrogen (N-Q) species $(9.5 \mathrm{HT} 30){ }^{10)}$. Sample name of KF8AN20-8ST30-9.5HT, for instance, means KF (KF1500) was heat-treated with all above modification methods in the order of thermal CVD, steam activation and then just heat-treatment. For comparison with acetonitrile treatment, n-heptane $(15 \mathrm{~mL})$ thermal CVD was conducted in addition, instead of the acetonitrile (20 mL) CVD, referred to as KF-8(C7)15-9.5HT308ST30. All prepared ACFs were evaluated by nitrate adsorption amount at $\mathrm{pH}$ around 3. Thirty milligrams of each modified KF samples was put into Erlenmeyer flask containing $15 \mathrm{~mL}$ of sodium nitrate $\left(\mathrm{NaNO}_{3}\right)$ solution. The starting solution $\mathrm{pH}$ and the initial concentration of nitrate were respectively about 3 and $200 \mathrm{mg}\left(\mathrm{NO}_{3}{ }^{-}\right) / \mathrm{L}(3.23 \mathrm{mmol} / \mathrm{L})$. The mixture was stirring for at least 12 hours at ambient temperature and equilibrium solution $\mathrm{pH}$ was adjusted between 2.8 and 3.5, most of the case $\mathrm{pH} 3.0$ 3.5. The initial and the equilibrium concentrations of nitrate were measured by an Ion Chromatography (Nippon Dionex KK, model ICS-1100). The adsorption amount in $\mathrm{mmol} / \mathrm{g}$ at equilibrium was calculated from the difference in concentrations and sample weight of $30 \mathrm{mg}$.

\section{Results and Discussion}

Fig. 1 shows the equilibrium adsorption amounts of pristine and various prepared adsorbents and the adsorption amounts of nitrate $\left(\mathrm{NO}_{3}{ }^{-}\right)$were varied from 0.25 to $0.71 \mathrm{mmol} / \mathrm{g}$ in which all adsorption was assumed to be progressed via ion exchange mechanism, because in our previous study, discharge of $\mathrm{Cl}^{-}$ from the adsorbent into the solution by exchanging with $\mathrm{NO}_{3}{ }^{-}$ was observed in all investigated similar carbonaceous anion ion-

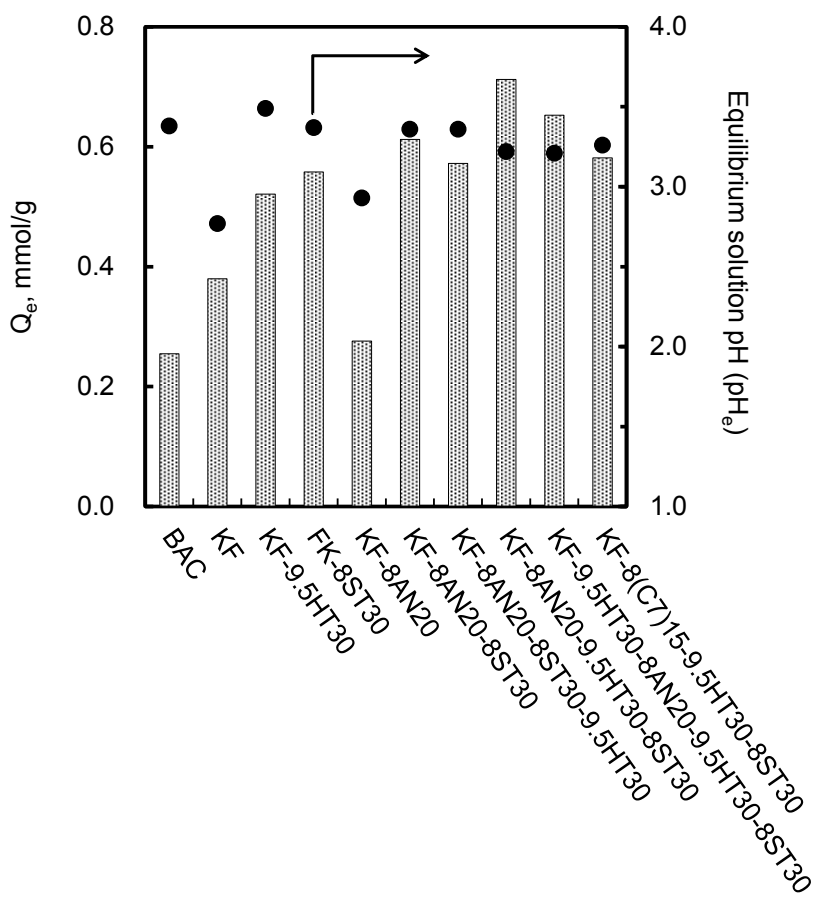

Fig. 1 Adsorption amount of $\mathrm{NO}_{3}{ }^{-}\left(Q_{\mathrm{e}}\right.$ in $\left.\mathrm{mmol} / \mathrm{g}\right)$ onto various carbonaceous ion-exchangers in aqueous solution. Black circle (•); equilibrium solution $\mathrm{pH}\left(\mathrm{pH}_{\mathrm{e}}\right)$. 


\section{Table 1 Properties of activated carbon (BAC) and activated carbon fiber (KF)}

\begin{tabular}{|c|c|c|c|c|}
\hline \multirow{2}{*}{\multicolumn{2}{|c|}{ Sample name }} & \multicolumn{3}{|c|}{ Textual and surface properties } \\
\hline & & $\begin{array}{l}\mathrm{S}_{\mathrm{BET}} \\
\mathrm{m}^{2} / \mathrm{g}\end{array}$ & $\begin{array}{c}\text { Pore } \\
\text { volume, } \\
\mathrm{cm}^{3} / \mathrm{g}\end{array}$ & $\begin{array}{c}\text { Pore } \\
\text { diameter, } \\
\mathrm{nm}\end{array}$ \\
\hline KF & & 1560 & 0.70 & 0.74 \\
\hline BAC & & 1380 & 0.60 & 0.57 \\
\hline \multirow[b]{2}{*}{$\begin{array}{l}\text { Sample } \\
\text { name }\end{array}$} & \multicolumn{4}{|c|}{ Bulk elemental composition } \\
\hline & $\begin{array}{c}\text { Carbon, } \\
\% \\
\end{array}$ & $\begin{array}{c}\text { Hydrogen, } \\
\% \\
\end{array}$ & $\begin{array}{c}\text { Nitrogen, } \\
\% \\
\end{array}$ & $\begin{array}{c}\text { Oxygen*, } \\
\%\end{array}$ \\
\hline KF & 88.4 & 0.6 & 1.7 & 9.3 \\
\hline $\mathrm{BAC}$ & 94.0 & 0.7 & 0.4 & 5.0 \\
\hline
\end{tabular}

*calculated by difference

exchangers ${ }^{11)}$. The adsorption amount on ion exchange resin of HP555 as a reference adsorbent was $1.4 \mathrm{mmol} / \mathrm{g}$, which was twice as large as the maximum adsorption amount of 0.71 $\mathrm{mmol} / \mathrm{g}$. BAC (bead-shaped activated carbon) purchased from Kureha Corporation is also a reference material. Adsorption amount of KF $(0.38 \mathrm{mmol} / \mathrm{g})$ was larger than that of BAC $(0.25$ $\mathrm{mmol} / \mathrm{g}$ ). As shown in Table 1, this is caused by higher surface area, higher pore volume, higher pore diameter and larger nitrogen content of KF than those of BAC, in spite of larger oxygen content of $\mathrm{KF}$ than $\mathrm{BAC}$, in which acidic oxygen functional groups can inhibit the nitrate adsorption. Both KF$9.5 \mathrm{HT} 30(0.52 \mathrm{mmol} / \mathrm{g})$ and $\mathrm{KF}-8 \mathrm{ST} 30(0.56 \mathrm{mmol} / \mathrm{g})$ were better than $\mathrm{KF}$, because oxygen reduction and further pore development from KF would be respectively achieved in KF9.5HT30 and KF-8ST30. In contrast, nitrogen doping with acetonitrile thermal CVD on KF led to the significant decline in adsorption amount of nitrate (KF-8AN20, $0.28 \mathrm{mmol} / \mathrm{g}$ ) compared to the original $\mathrm{KF}(0.38 \mathrm{mmol} / \mathrm{g})$.

However, additional steam activation at $800^{\circ} \mathrm{C}$ resulted in remarkable enhancement of adsorption capacity (KF-8AN20$8 \mathrm{ST} 30,0.61 \mathrm{mmol} / \mathrm{g}$ ) even more than KF-9.5HT30 and KF8ST30. Thereby, the acetonitrile thermal CVD would plug the pore structure of KF, whereas effective nitrogen species could be introduced into the structure of $\mathrm{KF}$ and oxygen content would be decreased at the same time, and then nitrogencontaining pore structure could be achieved by the second activation by steam at $800^{\circ} \mathrm{C}$ (the first activation was done in the commercial production), in which nitrogen rich surface should be remained by selectively reducing carbon element during the pore development. Further heat-treatment of KF$8 \mathrm{AN} 20-8 \mathrm{ST} 30$ at $950^{\circ} \mathrm{C}$ for the purpose of converting a part of doped nitrogen species into quaternary nitrogen (N-Q) could not successfully enhance the adsorption amount of nitrate (KF8AN20-8ST30-9.5HT30, $0.57 \mathrm{mmol} / \mathrm{g}$ ). This might be caused by shrunk pore structure and/or decrease in nitrogen content by the $950^{\circ} \mathrm{C}$ heat-treatment. On the other hand, when the heattreatment at $950^{\circ} \mathrm{C}$ was conducted just after KF-8AN20 and before $8 \mathrm{ST} 30$ treatment, the maximum adsorption amount could be observed in the study (KF-8AN20-9.5HT30-8ST30, 0.71 $\mathrm{mmol} / \mathrm{g}$ ), indicating that the order of treatments would play an important role to enhance the adsorption capacity. The heattreatment at $950^{\circ} \mathrm{C}$ of $\mathrm{KF}-8 \mathrm{AN} 20$ might effectively convert doped nitrogen species inside the ACF into quaternary nitrogen (Q-N) without significant loss of nitrogen, after that steam activation at $800^{\circ} \mathrm{C}$ would develop pore structure with remaining effective nitrogen inside the structure. In case of the insertion of heat-treatment of $\mathrm{KF}$ at $950^{\circ} \mathrm{C}$ before $8 \mathrm{AN} 20$ treatment for KF-8AN20-9.5HT30-8ST30, a slight decline in adsorption amount was observed (KF-9.5HT30-8AN209.5HT30-8ST30, $0.65 \mathrm{mmol} / \mathrm{g})$. The heat-treatment at $950^{\circ} \mathrm{C}$ of KF might shrink the pore structure of KF resulting in the slight decrease in the amount of nitrogen doping in the consecutive step. Furthermore, when n-heptane was used instead of acetonitrile for KF-8AN20-9.5HT30-8ST30 in the CVD treatment, as referred to as KF-8(C7)15-9.5HT30-8ST30, the adsorption amount was $0.58 \mathrm{mmol} / \mathrm{g}$ and the different amounts between 0.71 and $0.58 \mathrm{mmol} / \mathrm{g}$ could be respectively attributed to the presence and absence of effective nitrogen species; n-heptane could have decreased surface acidic oxygen by reduction but never increased nitrogen content. More detail characterization of the adsorbents will be required to elucidate the relationship between the properties of nitrogen doped ACF adsorbents and the adsorption amount of nitrate.

\section{Summary}

Activated carbon fiber (ACF) of KF1500 (KF) was modified using three heating methods under inert gas flow to prepare carbonaceous anion ion-exchanger. Sequential treatments of acetonitrile thermal $\mathrm{CVD}$ at $800^{\circ} \mathrm{C}$, heat-treatment at $950^{\circ} \mathrm{C}$ and then steam activation at $800^{\circ} \mathrm{C}(\mathrm{KF}-8 \mathrm{AN} 20-9.5 \mathrm{HT} 30-8 \mathrm{ST} 30)$ led to maximize the adsorption amount of nitrate anion $(0.71$ $\mathrm{mmol} / \mathrm{g}$ ) in aqueous solution and the maximum amount was 1.9 times larger than that of the original KF $(0.38 \mathrm{mmol} / \mathrm{g})$ but still a half of ion exchange resin of HP555 $(1.4 \mathrm{mmol} / \mathrm{g})$.

\section{Acknowledgements}

This study was funded in part by the Japan Society for the Promotion of Science (JSPS) under a Grants-in-aid for Scientific Research (C) (No. 26340058). Gratitude is extended to Ms. Hiroko Kanasugi and Ms. Shizuka Ishibashi, Safety and Health Organization, Chiba University for their dedicated supports in the experiments. We also thank Prof. Dr. Fumio Imazeki, the head of Safety and Health Organization, Chiba University, for his encouragement and the financial support on our study. 


\section{References}

1) H. Tamon and M. Okazaki, J. Colloid Interface Sci., 179, 181 (1996)

2) K. M. Mena Aguilar, Y. Kose, Y. Amano, M. Machida and F. Imazeki, J. Environ. Chem., 26, 109 (2016).

3) M. Machida, S. Chensun, Y. Amano and F. Imazeki, Bull. Chem. Soc. Jpn., 88, 127 (2015).

4) M. Machida, T. Goto, Y. Amano and T. Iida, Chem. Pharm. Bull., 64, 1555 (2016).

5) K. Ota, Y. Amano, M. Aikawa and M. Machida, Appl. Surf. Sci., 276, 838 (2013).

6) T. Goto, Y. Amano and M. Machida, TANSO, 276, 2 (2017).

7) J. H. Bitter, S. van Dommele and K. P. de Jong, Catal. Today, 150, 61 (2010).

8) A. Dioum and S. Hamoudi, J. Porous. Mater., 21, 685 (2014).

9) Z. Yang, Y. Xia, X. Sun and R. Mokaya, J. Phys. Chem. B, 110, 18424 (2006).

10) J. R. Pel, F. Kapteijn, J. A. Moulijn, Q. Zhu and K. M. Thomas, Carbon, 33, 1641 (1995).

11) T. Goto, Y. Amano and M. Machida, J. Chem. Eng. Jpn., 50, 692 (2017). 